\title{
INTERVIEW
}

\section{Care for LGBTQIA Communities When Advocacy Is All About Inclusion: A Conversation With Jackie Baras, MSN, MBA, RN}

\author{
Lorraine Steefel, DNP, RN, CTN-A
}

\begin{abstract}
Nurses have the obligation and duty to care for all people (American Nurses Association, 2015), and to treat them with dignity, respect, and compassion (Fowler, 2015). To address equitable care of LGBTQIA people in her community, Jackie Baras, MSN, MBA, RN, serves as LGBT Navigator at Robert Wood Johnson University Hospital/RWJBarnabas Health in New Brunswick, New Jersey. As a transgender woman, Jackie advocates as liaison and representative for all LGBTQIA patients and employees, focusing on health promotion and disease prevention, addressing knowledge gaps, and identifying community referrals, while working closely with hospital and clinical leadership to ensure that health-care services are coordinated seamlessly. Here, Jackie discusses her advocacy for equitable care for LGBTQIA communities, and ways nurses can provide culturally congruent care.
\end{abstract}

Keywords: LGBTQIA; transgender; nursing care of LGBTQIA people; nursing care of transgender community

Lorraine Steefel: It's been a little over a year since you've taken on your role as LGBTQIA Navigator in your organization. Please describe the work you've been doing.

Jackie Baras: Rather than patient care, I prefer to say that I and my colleagues provide humanizing care to people who live with discrimination as soon as they go out their front doors. For trans people, those whose gender identity does not coincide with their sex assigned at birth, I am with them coordinating care as they transition, going through hormone therapy and/or surgery, in addition to provision of their basic health needs. At PROUD (Promoting Respect, Outreach, Understanding, and Dignity) Family Health Clinic in Somerset, New Jersey, for example, members of the LGBTQIA community receive comprehensive health care, from primary care to hormone therapy, health education and counseling, HIV prevention, and support groups. Robert Wood Johnson (RWJ) Somerset is the first hospital in New Jersey to offer specialized primary care for this community.

We provide a safe place that encourages the LGBTQIA community to express their problems and needs for us to help address. Much of our work involves social issues, since the social stigma experienced, either actual or perceived, takes an emotional and social toll. Part of my role is to serve as education facilitator in Proudly Me! Transgender Edu-port (Education and Support) Program, a free monthly education and support program to help transgender and non-binary-conforming community members learn about community resources and engage in dialogue. I also co-chair the PROUD Business Resource Group (BRG), which provides support for colleagues, fosters career development, and contributes to cultural sensitivity in the work environment.

But what happens after patients leave RWJ? To address this question, I promote advocacy at the state and national levels-being visible: for example, I present lectures and share my own stories both as a provider and a member of the transgender community.

Steefel: You mention safety (a safe place) as a key issue. Please explain.

Baras: People who are not transgender (the frequently-used term for non-transgender people is cisgender) do not experience the general feeling of harm that could come to us just from leaving our homes. State laws vary when it comes to protection or lack of protection against those who would bully or do physical harm to us. In one state where I stayed for a nursing conference, I didn't dare leave the hotel, for safety's sake. 


\section{It takes courage for transgender people to come out and to seek care, especially when many of us have experienced negative interactions with uninformed providers in the past.}

In this milieu, it takes courage for trans people to come out and to seek care, especially when many transgender people have experienced negative interactions with uninformed providers in the past.

Steefel: How can nurses set the stage for a healthcare environment that feels safe?

Baras: Communication, verbal and non-verbal, is so important. If nurses aren't sure how to address a trans person, they should ask, "How would you like me to address you? What pronouns do you use when referring to yourself?" What nurses say and how they say it is important; for example, facial expressions can mean the difference between making someone feel welcome or uncomfortable.

If nurses make a mistake, they should apologize and move on rather than make a big deal of something and continuing on and on with "I'm sorry, I'm sorry." This just makes things worse.

Just as with all patients, it takes time to put people at ease and establish trust- to treat the whole person, mind and body.

Steefel: What is the most common gaffe that nurses make when it comes to working with trans people?

Baras: Here's an example: When doing an intake interview, the nurse asks the patient, "Is your husband (or wife) here with you?" When seeking healthcare answers, nurses need to know to ask the right questions to get the right answers. For instance, rather than assume the traditional husband or wife relationship, the nurse should ask whether there is a significant other. And questions must be appropriate to the situation. Nurses shouldn't ask patients about gender, sex assigned at birth, or transition-related procedures if this information is not directly relevant to their care.

Steefel: How can nurses prevent gaffes?

Baras: Education is key to gaffe prevention. I suggest that nurses read evidence-based studies that provide accurate information regarding this popu- lation, our needs, and how to address these needs, and keep updated regarding their understanding of the health issues that face trans people. Education negates assumptions. For example, nurses learn that the transgender experience is diverse. Not everyone takes hormones or undergoes genital surgery, for example.

Steefel: Are there biases embedded into structures and process of care that are insensitive and could cause pain?

Baras: Bias begins in the brain; it means seeing people as different from ourselves and judging them. Trans people tend to experience higher rates of physical and mental illness and prejudice than the general population (Schreiber, 2016), and are in need of reliable, unbiased health care. Yet, right from the beginning of their interface with health care, the intake questions often demonstrate bias embedded in the system, which shows a lack of inclusion. At RWJ, the question regarding gender has been expanded. The ID bracelet shows last name, legal first name, and preferred name. For example, when Max might be the legal name, a transgender woman may prefer to be called Maxine. The nurse looks for and uses the preferred name.

Steefel: What is the responsibility of clinical leaders in assuring that their teams are prepared, aware, and knowledgeable in the care of trans people?

Baras: Clinical leaders have the responsibility to educate their teams, cultivating greater knowledge and awareness about unconscious (or conscious) bias within health-care cultures as they prepare staff members to provide care for trans people. I believe in the face-to-face approach to learning to establish an understanding of the basic knowledge that staff members need. During orientation and during mandatory meetings, for example, I bring in members of the trans community to talk with staff. I have staff members role play intake interviewing. This approach fosters respect and makes members of the trans community feel that they are being included in the health-care conversation. Inclusion is what this is all about. Inclusion begins with "I."

Steefel: How would you summarize the significance of what you do?

Baras: I relate my role to my community. As a transgender woman, it is a challenge to be one's authentic self. My goal is to help others like me, struggle though it may be, to rise to the challenge. 


\section{Education is key to gaffe prevention; read evidence-based studies that provide accurate information about this population, our needs, and how to address these needs.}

\section{REFERENCES}

American Nurses Association. (2015). ANA position statement on risk and responsibility in providing nursing care. Retrieved from https://www.nursingworld.org/ 4ad $4 \mathrm{a} 8$ /globalassets/docs/ana/riskandresponsibility.pdf

Fowler, M. (2015). Guide to the code of ethics for nurses: Development, application and interpretation (2nd ed.). Silver Springs, MD: American Nurses Association.

Schreiber, K. (2016, December 6). Why transgender people experience more mental health issues. Psychology Today. [web-log-post]. Retrieved from https:/ / www.psycholo gytoday.com/us/blog/the-truth-about-exercise-addict ion/201612/why-transgender-people-experience-more -mental-health
Disclosure. The author(s) have no relevant financial interest or affiliations with any commercial interests related to the subjects discussed within this article.

Funding. The author(s) received no specific grant or financial support for the research, authorship, and/or publication of this article.

Correspondence regarding this article should be directed to Lorraine Steefel at lsteefel@gmail.com

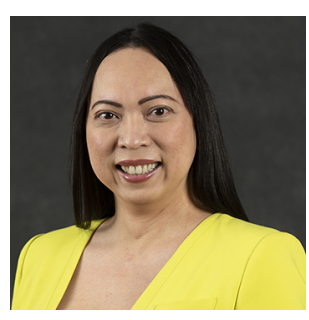

Jackie Baras, RN, MSN, MBA, (she/ her/hers), is LGBT Navigator and Quality Nurse Manager of PeriOperative Services at Robert Wood Johnson University Hospital/RWJBarnabas Health in New Brunswick, New Jersey.

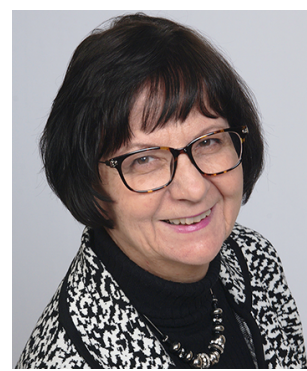

Lorraine Steefel, DNP, RN, CTN-A, (she/her/hers), is Director of LTS Writing and Editorial Consulting Services in Marlboro, New Jersey. 